Claremont Colleges

Scholarship@ Claremont

All HMC Faculty Publications and Research

HMC Faculty Scholarship

$1-1-1977$

\title{
Applying Mathematics Without a License
}

Melvin Henriksen

Harvey Mudd College

\section{Recommended Citation}

Henriksen, Melvin. "Applying mathematics without a license." The American Mathematical Monthly 84.8 (1977): 648-650.

This Article is brought to you for free and open access by the HMC Faculty Scholarship at Scholarship @ Claremont. It has been accepted for inclusion in All HMC Faculty Publications and Research by an authorized administrator of Scholarship @ Claremont. For more information, please contact scholarship@cuc.claremont.edu. 


\section{APPLYING MATHEMATICS WITHOUT A LICENSE}

BY

MELVIN HENRIKSEN

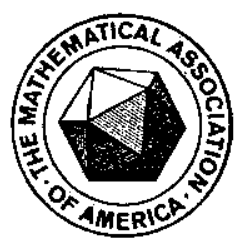

Reprinted from the AMERICAN MATHEMATICAL MONTHLY

Vol. 84, No. 8, October 1977

pp. $648-650$ 


\title{
APPLYING MATHEMATICS WITHOUT A LICENSE
}

\author{
MELVIN HeNRIKSEN'
}

A recent educational experience made me realize the extent to which the mathematical community has become fragmented and how this has served to inhibit communication both with others and ourselves. What used to be called a department of mathematics has split into several parts by adding departments of computer science and statistics for openers, not to mention separate departments of applied mathematics in some places, and various specialized organizations of mathematicians plying their trade in colleges of agriculture, commerce, or engineering under odd sounding names. Undergraduate colleges too small to afford so many different departments make up for this lack by offering options within a major in mathematics which reflect these differences. Since most methods used to finance departments or programs depend heavily on enrollments, walls are erected which serve to make exploration of more than one brand of mathematics by the student difficult; even as an undergraduate.

If the prime educational goal is to train people to push back the frontiers of knowledge in these areas, perhaps a high degree of specialization is needed. But I wonder if even such a noble goal justifies forcing college sophomores to choose a specialty so early that we end up with Ph.D's in computer science who are shaky about the definition of a limit of a function, pure mathematicians who have never been exposed to statistics, and statisticians who have never been exposed to either abstract algebra or topology. Not only do we create a yawning gap between "pure" and "applied" mathematics, but we also maintain sharp differences between various kinds of the latter which demand, seemingly, the undivided attention of the student beginning at an early point in his college studies. It is as if one needs a license to apply mathematics obtainable only after many years of a highly specialized apprenticeship.

Harvey Mudd College is an undergraduate institution with an enrollment of about 450, and (with a small number of exceptions) all of our students major in chemistry, engineering, mathematics or physics. Despite this small size, our program in mathematics has succumbed to many of the trends towards early specialization mentioned above. Through our Mathematics Clinic, however, we have managed to get some of our majors (and ourselves) to apply mathematics to a variety of problems obtained from industrial and governmental organizations. These are not classroom exercises in applicable mathematics. The organization involved pays Harvey Mudd College to assign a team consisting of a faculty member and a group of students to work on an open-ended problem of real concern to them and produce a report on their progress after some pre-assigned time (usually one or two semesters). Students work on clinic projects while taking other courses. The Mathematics Clinic is run in cooperation with the Claremont Graduate School, and participants may come from any of the Claremont Colleges².

The Mathematics Clinic began in 1973 and is an offshoot of a corresponding operation started much earlier by our engineering department. The prerequisites for participation in a particular project vary with the problems involved, and different students may contribute different skills. The projects taken on so far include mathematical modeling of air pollution and of an industrial problem involving light scattering, developing a kinematic handbook for missile design, and the mathematical modeling of the history of a compacting sedimentary basin. The mathematical techniques used include

\footnotetext{
1 This article was prepared while the author was on leave at the University of Manitoba in Winnipeg, Manitoba, Canada.

${ }^{2}$ The Claremont Graduate School, Claremont Men's College, Harvey Mudd College, Pitzer College, Pomona College, and Scripps College form a group of independent colleges located in Claremont, California which share certain facilities in common and cooperate by mutual consent in some ways. Each has is own curriculum and degree requirements, but students are permitted to take some of their courses at a Claremont College other than their own.
} 
computer simulation, ordinary and partial differential equations, the finite element method, probability, statistics, and, of course, linear algebra. The students participating must be able to read background material relevant to a particular project. Hence there is a limit to the sophistication of the techniques that are used.

My colleague George Orland and I supervised a project on juror utilization for the Superior Court of the County of Los Angeles in the spring of 1975. Our goal was to produce a method for reducing the number of people who have to be called to jury duty without slowing down the flow of court cases coming to trial or initiating legislative changes. Both of us are "pure" mathematicians whose research interests are in functional analysis, general topology and the structure of rings. The students ${ }^{3}$ ranged from a freshman studying the calculus, through some seniors with knowledge of probability and statistics, and a graduate student aiming for a career in junior college teaching. None of us were certified as applied mathematicians or had any background in law, but we thought we could improve the current jury selection system which kept large numbers of people in attendance each day who never got into a courtroom. Since we had to come up with some answers within a semester, we decided to concentrate our efforts in one courthouse, and chose the one in Pomona, California because of its geographic proximity and the reasonably small volume of cases handled there.

Jumping ahead in the story, we did succeed in devising a rather crude method which, if followed, would reduce the number of jurors needed in the Pomona Courthouse by at least $37 \%$ and save the county at least $\$ 73,000$ per year. Moreover, with more effort, the method could be improved and with modification applied to other courthouses in Los Angeles County. George Orland and I have reported on this in full in a legal journal [1], including our difficulties in getting our system implemented, which continue until now. Only a little of [1] is reported below.

Originally we thought we could readily devise a mathematical model, test its effectiveness with the aid of data in court records, modify it accordingly, and refine it by a process of successive approximation to reality. Such data turned out not to be readily available. For example, while we could find out how many people had been sent into a courtroom (usually in groups of 30 to 40 ) to be examined by attorneys as possible jurors for a particular trial, no record was kept of how many of them were actually questioned before a jury of 12 (sometimes with 1 or 2 alternates) was completed. So we had to gather our own data, and to talk with the jury commissioner's office, attorneys, judges and court clerks to obtain data. To win cooperation we had to explain our purpose, and then listen to an unsolicited discourse on why mathematics could be of no help. One by one, they told us essentially the same story concerning the great variability involved in the jury selection process and emphasized their point with the fact that over 700 prospective jurors had to be examined to get a jury for the murder trial in which Charles Manson was the defendant. Each of them seemed convinced that we were seeking some universal number of jurors that would provide efficiently for the needs of the courthouse every day it is in session. Only by listening to their discourse, and convincing them we were not quite so naive as they had thought, could we get them (sometimes reluctantly) to answer our questions. The overwhelming majority of those whom we questioned held college degrees; yet none of them seemed to realize that mathematical techniques could deal with uncertainty.

The mathematical techniques needed were not at all sophisticated. Computer programming was a vital tool for digesting the data we had gathered. Some elementary statistics was needed to determine the number of jurors that had to be examined to complete a jury to within a pre-assigned confidence interval. Usually, 25 is a good approximation. (Clearly "sensational" trials have to be handled separately. These are known well in advance, are few in number, and do not occur at all in outlying courthouses like the one in Pomona). Since a new jury trial cannot start without an available courtroom, to get an upper bound for the number of jurors needed on the next day, it is enough to multiply the number of courtrooms that have a chance of becoming vacant by 25 .

\footnotetext{
${ }^{3}$ John Lavrakas of the Claremont Graduate School, David Abrahamson and Joseph Coquillard of Harvey Mudd College, Deborah Taper of Pitzer College, John Irvine and Greg Johnson of Pomona College.
} 
The interested reader can examine [1] for possible refinements of this scheme. The bulk of the time spent was in interviewing people and gathering data; as opposed to learning about recent developments in applied mathematics. Even this crude approach can save a lot of the taxpayers money and reduce considerably the time wasted by citizens called for jury duty.

As of this writing, we have not been encouraged to refine our techniques, nor are they being used to their full potential, despite accurate publicity on our project by the Los Angeles Times on August 21,1975 . I can only conjecture as to why, but two reasons seem very plausible. The budget of the Superior Court of Los Angeles County was cut substantially for 1975-76, and there is an initial cost of any administrative reform which could not be recovered later because of the nature of government financing. (The standard reward for efficiency in public institutions is usually more work and a budget cut). Also, while the mathematics involved seems quite elementary to us, it is less than comprehensible to those who bear the responsibility for changing the system. This latter problem, pointed out so well by C.P. Snow in [2] seems no closer to a solution now than it was then.

What about the rewards to the mathematicians working on problems of this kind? We never considered sending [1] to a mathematical (or statistical or computer science) journal since the tools used are too elementary to add to the technical knowledge of their readers. Surely no young man trying to get tenure today in any academic department in the mathematical sciences at a university can afford to work on a project whose results cannot be published in a mathematical journal. Yet we did apply mathematics to a problem of social importance. Some years ago, while I was on the faculty of a midwestern state university I had a colleague who had co-authored quite a few papers with social scientists. He had applied the elements of probability, statistics, or linear algebra to problems considered important by a variety of psychologists and sociologists. To them, he was the most valuable member of the department of mathematics. His mathematical colleagues gave him little or no credit for these efforts since they considered the mathematical content of the papers trivial, and he left after a while. It is the sophistication of the tool used about which we seem to care, as opposed to the problem on which it is being used.

The renaissance man is no more likely to return to the mathematical scene than the passenger pigeon is to reappear in the skies of North America. Mathematics has grown too much for any individual to keep up with the current literature in all but a small part of it, or to be able to teach at the graduate level in all of the areas we now call the mathematical sciences. But in our zeal to get research done and to train young people to succeed us, we are in danger of becoming Fachidioten capable of communicating only with a small group of mathematicians with the same research interests. Indeed, when I find that I cannot read many research articles in fields close to my own because the author won't take the trouble to explain the notation used or give a reference to where it is defined, I wonder if we are not in danger of joining the passenor pigeon.

Without a space race or ever expanding culege enrollments to provide a justification for our activities, we must seek other ways to provide employment for young mathematicians than learning how to reproduce themselves. Perhaps teaching them and ourselves how to apply mathematics without the total commitment involved in getting a license can help.

Much more thorough descriptions of the Mathematics Clinic are given by Jerome Spanier in [3] and [4].

\section{References}

1. Melvin Henriksen and George Orland, On the juror utilization problem, The Jurimetrics Journal, 16 (1976) $318-333$.

2. C. P. Snow, Two Cultures and The Scientific Revoiution, Cambridge University Press, New York, 1962.

3. J. Spanier, The Mathematics Clinic: an innovative approach to realism within an academic environment, this MonThly, 83 (1976) 771-775.

4. —— The Claremont Mathematics Clinic, Siam Review, 19 (1977) 536-549.

Department of Mathematics. Harvey Mudd College. Claremont. Ca 91711. 